\title{
Acoustic Emission Simulation on Coal Specimen Subjected to Cyclic Loading
}

\author{
Huiqiang Duan (iD) ${ }^{1}$ and Depeng $\mathrm{Ma}$ (D) $^{2}$ \\ ${ }^{1}$ School of Mining and Coal, Inner Mongolia University of Science and Technology, Baotou 014010, China \\ ${ }^{2}$ School of Water Conservancy and Civil Engineering, Shandong Agricultural University, Tai'an 271018, China \\ Correspondence should be addressed to Huiqiang Duan; duanhuiqiang11@163.com
}

Received 6 November 2019; Revised 13 May 2020; Accepted 23 May 2020; Published 29 June 2020

Academic Editor: Chunshun Zhang

Copyright (c) 2020 Huiqiang Duan and Depeng Ma. This is an open access article distributed under the Creative Commons Attribution License, which permits unrestricted use, distribution, and reproduction in any medium, provided the original work is properly cited.

\begin{abstract}
The damage and failure state of the loaded coal and rock masses is indirectly reflected by its acoustic emission (AE) characteristics. Therefore, it is of great significance to study the AE evolution of loaded coal and rock masses for the evaluation of damage degree and prediction of collapse. The paper mainly represents a numerical simulation investigation of the AE characteristics of coal specimen subjected to cyclic loading under three confining pressures, loading-unloading rates, and valley stresses. From the numerical simulation tests, the following conclusions can be drawn: (1) The final cycle number of coal specimen subjected to cyclic loading is significantly influenced by the confining pressure, followed the valley stress. With the increase in confining pressure or valley stress, the cycle number tends to increase. However, the loading-unloading rate has a little influence on it. (2) The AE counts of coal specimen subjected to cyclic loading are greatly influenced by the confining pressure and the valley stress. With the increase in the confining pressure, the cumulative $\mathrm{AE}$ counts at the 1st cycle tend to increase but decrease at a cycle before failure; with the decrease in the valley stress, the cumulative AE counts per cycle increase in the relatively quiet phase. However, the loadingunloading rate has a little influence on it. (3) The failure mode of coal specimen subjected to cyclic loading is significantly influenced by the confining pressure. Under the uniaxial stress state, there is an inclined main fractured plane in the coal specimen, under the confining pressures of 5 and $10 \mathrm{MPa}$, the coal specimen represents dispersion failure. The loading-unloading rate and valley stress have little influence on it. (4) The AE ratio is proposed, and its evolution can better reflect the different stages of coal specimen failure under cyclic loading. (5) The influence of confining pressure on the broken degree of coal specimen subjected to cyclic loading is analyzed, and the higher the confining pressure, the more broken the failed coal specimen.
\end{abstract}

\section{Introduction}

In underground coal mining, many types of coal pillars need to be set. In addition to the static loading, these pillars have also been subjected to the repeated stress induced by mining and excavation. Under these stresses, the damage of coal pillars increases and the strength decreases, eventually very likely leading to collapse. Especially in deep mine, the failure of coal pillars often occurs in the form of rock burst [1-3]. Therefore, it is of great significance to study the precursory characteristics of coal mass failure for the safe production of coal mine. According to the research of the German scholar Kaiser, the loaded rock or materials release strain energy in the form of elastic wave, and this phenomenon is called acoustic emission (AE) [4-8]. The AE signals have been proved to be an important manifestation form and feedback of rock deformation and fracture [9-13]. Since the AE signals contain abundant precursory information of rock damage, the internal state and damage degree of rock can be predicted and evaluated by analyzing the characteristics of AE signals [14-17]. Therefore, to research the AE evolution law of coal mass from damage to failure under repeated stress is an important means to prevent coal mine from disasters and accidents.

Now, many research achievements have shown that there are two AE effects, namely, Kaiser and Felicity effects. Both effects are an indirect reflection to the damage and failure state of the loaded rock and closely related to the rock 
structure and loading conditions [18-20]. Besides, the rock types and test conditions have a significant influence on the AE characteristics. For example, Liu et al. [21] studied the $\mathrm{AE}$ characteristics of muddy sandstone under one full freeze-thaw loading cycle through triaxial seepage tests. The variation of rock permeability corresponds well to $\mathrm{AE}$ amplitude. AE signals are not active in the initial loading stage under higher confining pressure; on the contrary, the maximum values of $\mathrm{AE}$ energy and amplitude increase during the whole test. Su et al. [22] investigated the AE evolution of granite rock specimens in true triaxial rockburst tests. On the eve of the rock burst, the "quiescent period" could be observed in the evolution of the AE hits, the time-dependent fractal dimensions of the AE hits continuously decrease, and the main frequency of the AE showed decreasing trends. Thus, the evolution of AE signals can be used as key information for rock-burst prediction. Tian et al. [23] researched the AE properties of sedimentary rocks subjected to the high-velocity waterjet impingement loading. They found that there are obvious differences in AE signal frequencies between the fluid dynamics and the rock failure. The main frequencies of the rock failure are within the range of $100-200 \mathrm{kHz}$, while the frequencies of the fluid dynamics are below $50 \mathrm{kHz}$. Wang et al. [24] studied the AE characteristics in karst limestone failure under uniaxial and triaxial compression. The AE activity of rock under triaxial compression differs from that under uniaxial compression. In the uniaxial compression test, the peak $\mathrm{AE}$ activities occur near the peak stress of the rock. In the triaxial compression test, the AE activities of the rock samples first decreased and then increased with an increase in the confining pressure, and the AE activity exhibited a certain lag, the AE peak appears at a sharp stress decrease and rock macroscopic failure. Zhang et al. [25] studied the acoustic emission characteristics of salt rock under uniaxial conventional compression and cyclic loading. Compared with conventional compression, the cyclic loading weakens the $\mathrm{AE}$ events of rock. The Kaiser effect is mainly dependent on rock properties and loading condition. Fan et al. [26] studied the AEs from salt in conventional fatigue tests (CFTs) and discontinuous cyclic loading tests with the zero loading stress intervals (ZLIs). In the CFTs, the AE counting rate decreased gradually and reached a plateau before a rapid increase prior to the failure. In the ZLI tests, the AE activity evolution with time is very strongly dependent on the ZLI length and increases with its growth. Some other scholars have also carried out abundant research on the AE characteristics of different types of rocks under varying loading conditions $[15,27-33]$.

Through analysis of existing literatures, many achievements have been obtained on the AE characteristics of highstrength rocks subjected to cyclic loading. Because there are abundant microdefects in coal mass, it is difficult to process it into a standard specimen, and so the cyclic loading test on a coal specimen is relatively deficient. As is known to all, lab tests do be the main method to study the AE characteristics of rock materials. But, in lab tests, the specimen can be used for only one destructive test without the repeatability, which leads to the poor accuracy of the test results. As for coal specimens with great discreteness in mechanical properties, the accuracy of lab tests is even worse. Besides, the lab tests are also limited by the test conditions and costs, and sometimes difficult to carry out. Thus, the numerical simulation method has gradually become a popular way in solving the problems on rock mechanics for its repeatability, easy implementation, high efficiency, and low cost [34]. Based on the above, in this paper, first, the AE characteristics of coal specimen subjected to cyclic loading are studied by using Particle Flow Code (PFC), and then, the AE characteristics and damage evolution of coal specimens are explored.

\section{Establishment of the Model and Calibration of Meso-Parameters}

2.1. Introduction of PFC. PFC is computing software developed by Itasca Company, USA. It has been widely used in the study of basic mechanical properties of rock materials, medium fracture, and crack development. The basic principle of PFC comes from the molecular dynamics, which studies the mechanical properties and behavior of the medium from the point of view of micro-structure [35].

There are two basic units in PFC, namely, particle and wall. The particles are used to form the research object. The walls are as a constraint to control the movement of particles. There are two contact models in PFC: linear model and linearpbond model. In the linear model, the contact between two particles is abstracted as an infinitesimal-sized plane, and the mechanical behavior of the contact plane is described by using spring elements and damper elements, which are parallel to each other. The spring element describes the linear elasticity of the contact plane, and the damper element describes the viscous properties. Because the contact plane is infinitely small sized, it can only transmit force. The linearpbond model adds bonding property on the basis of the linear model. Because the bonding element is in parallel with the spring element, this bond is also called a parallel bond. The parallel bond can be abstracted as a bonding material with constant stiffness and certain strength between two particles. The strength properties of parallel bond conform to the Mohr-Coulomb criterion. When the bond is destroyed, the linearpbond model changes from the bonding state to unbonding state, and the properties of nonbonding linearpbond model is identical with the linear model. Because the contact plane of the linearpbond model has a certain size, it can transfer force and moment.

2.2. Establishment of the Numerical Model. In this paper, the PFC 2D software is employed and the bonded particle model (BPM) is used to simulate the AE properties of coal specimens. The established model height is $100 \mathrm{~mm}$, with a width of $50 \mathrm{~mm}$. In the simulation test, the smaller the particle size, the more accurate the simulation results, but this also significantly reduces the computing efficiency. If the particle size is too large, the reliability of simulation results is worse and difficult to reflect the real mechanical properties of specimens. Therefore, in the numerical simulation, it is necessary to make a trade-off between computing accuracy 
and efficiency to determine the reasonable number and size range of particles.

The research achievements show that when the average particle size is less than $2.5 \%$ of the model minimum length, the better simulation results can be achieved [36]. In addition, the critical time-step of the model can be expressed as follows [35]:

$$
t_{\text {crit }}=\left\{\begin{array}{l}
\sqrt{\frac{m}{k^{\text {tran }}}}, \\
\sqrt{\frac{I}{k^{\text {rot }}}},
\end{array}\right.
$$

where $m$ is the mass; $k^{\text {tran }}$ and $k^{\text {rot }}$ represent the translational and rotational stiffness, respectively; and $I$ is the moment of inertia of the particle.

The model components in PFC are conceptualized as a collection of discrete bodies (composed of disk shaped balls/ pebbles in 2D; spherical balls/pebbles in 3D) and springs. Each body may have a different mass, and each spring may have a different stiffness. A critical time-step is found for each body by applying equation (1) separately to each degree of freedom, assuming that the degrees of freedom are uncoupled. The stiffness is estimated by summing the contribution from all contacts using only the diagonal terms of the contact stiffness matrix. The final critical time-step is taken to be the minimum of all critical time-steps computed for all degrees of freedom of all bodies [35].

Equation (1) shows that if there is a large difference in particle size, the computing efficiency of numerical simulation will be greatly reduced.

Through repeated debugging and considering the time cost, the size range of particles in the model was determined to be from $0.35 \mathrm{~mm}$ to $0.55 \mathrm{~mm}$. There generated 6945 particles in all. The linearpbond contact model is used between particles. The established model is shown in Figure 1. Four walls are generated around the model; the top and bottom are loaded walls, and the left and right are servo walls (deleted in uniaxial simulation). The linear contact model is used between walls and particles. In order to eliminate the end-restraint, the friction coefficient is set to 0 .

\subsection{Lab Test and Meso-Parameters Calibration}

2.3.1. Lab Test. The big block of coal samples were from No. 16 upper coal seam of Yangcun Mine's No. 10602 coal face in Shandong, China. Each sample was processed into several standard cylindrical specimens with a diameter of $50 \mathrm{~mm}$ and a height of $100 \mathrm{~mm}$, which is suggested by the International Society for Rock Mechanics (ISRM). Conventional compression tests were conducted using the MTS815.02 rockmechanics test system (MTS Systems Corporation, Eden Prairie, MN, USA) from the China University of Mining and Technology, and the test was employed using the displacement control mode with a loading rate of $0.003 \mathrm{~mm} / \mathrm{s}$.

2.3.2. Meso-Parameters Calibration. There is no clear criterion for the calibration of meso-parameters in numerical

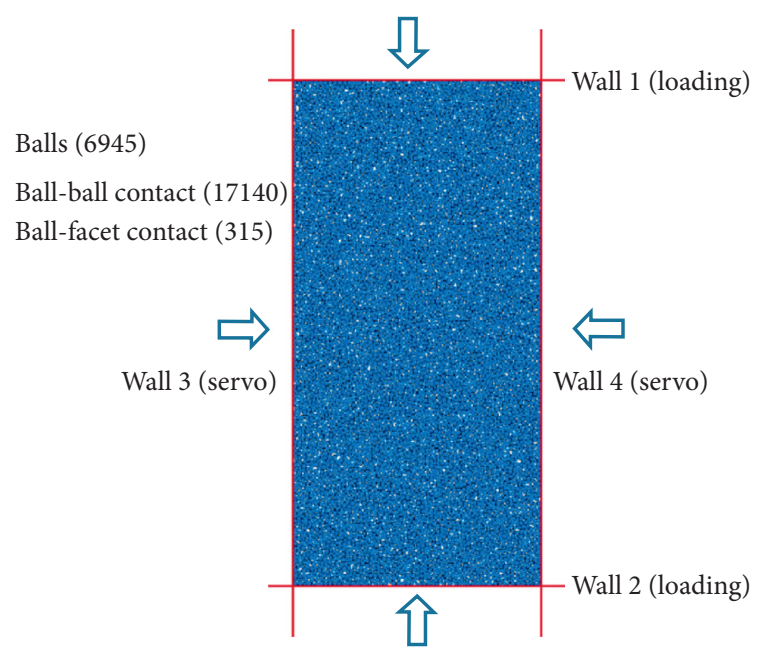

FIgURE 1: The established numerical model.

simulation. Generally, when using the same set of mesomechanical parameters, if the simulation stress-strain curves under different confining pressures are in good coincidence with the lab test curves, the model can be considered reliable $[37,38]$. However, this set of meso-parameters should be determined by trial-error method.

There is a sensitiveness of loading rate in the strength and deformation characteristics of rock. So, the conventional compression test with different loading rates is required in numerical simulation tests to obtain the whole process curve of static stress-strain corresponding to lab tests. Taking the conventional uniaxial compression test as an example, the axial stress-strain curves of coal specimen under different loading rates are shown in Figure 2. When the loading rate is less than or equal to $0.02 \mathrm{~m} / \mathrm{s}$, the peak strength and peak strain of coal specimen in the conventional compression simulation test tend to be steady. So, for the model in this paper, the loading less than or equal to this rate is regarded as the static.

Through repeated debugging, under the confining pressure of 0,5 , and $10 \mathrm{MPa}$, the conventional compression stress-strain curves of the simulation test and lab test are obtained, shown in Figure 3. The detailed meso-parameters are shown in Table 1. The comparison of peak strength and strain at stress peak point in the two tests is shown in Table 2, and the error between them is less than $6 \%$. This shows that the numerical model after meso-parameter calibration can accurately reflect the mechanical properties of coal specimen.

\section{Simulation Test of Coal Specimen Subjected to Cyclic Loading}

In the lab test, when the friction-type $\mathrm{AE}$ signals are very strong, the $\mathrm{AE}$ monitoring system will record it. It is no doubt that these strong friction-type AE signals will decrease $\mathrm{AE}$ system reliability in monitoring material damage and failure. In the numerical simulation test, the bond breakage is continuously monitored by the FISH program of PFC, and the counting number of bond breakage according to the 


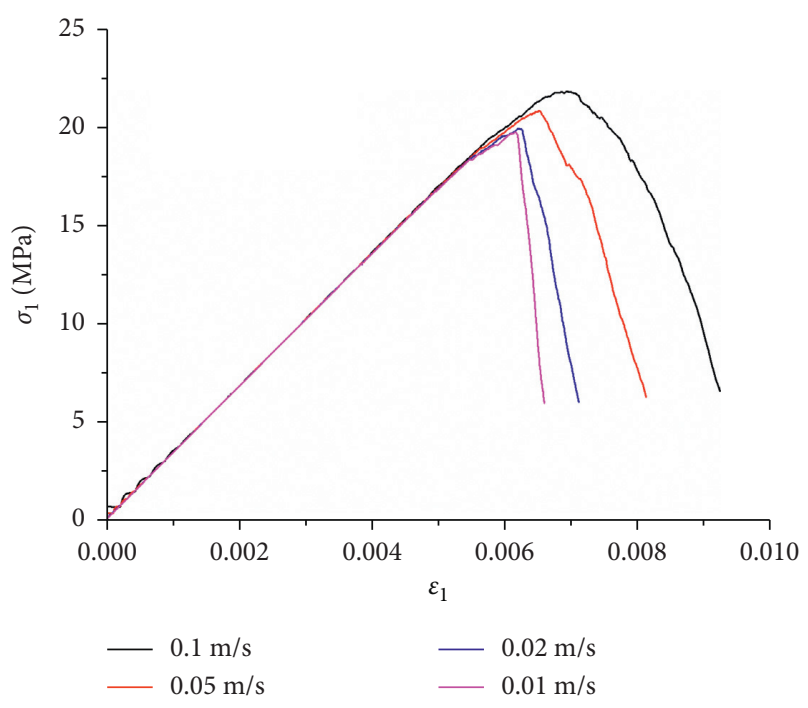

FIGURE 2: Conventional compression simulation stress-strain curves under different loading rates. Symbols $\sigma_{1}$ and $\varepsilon_{1}$ represent the axial stress and axial strain, respectively.

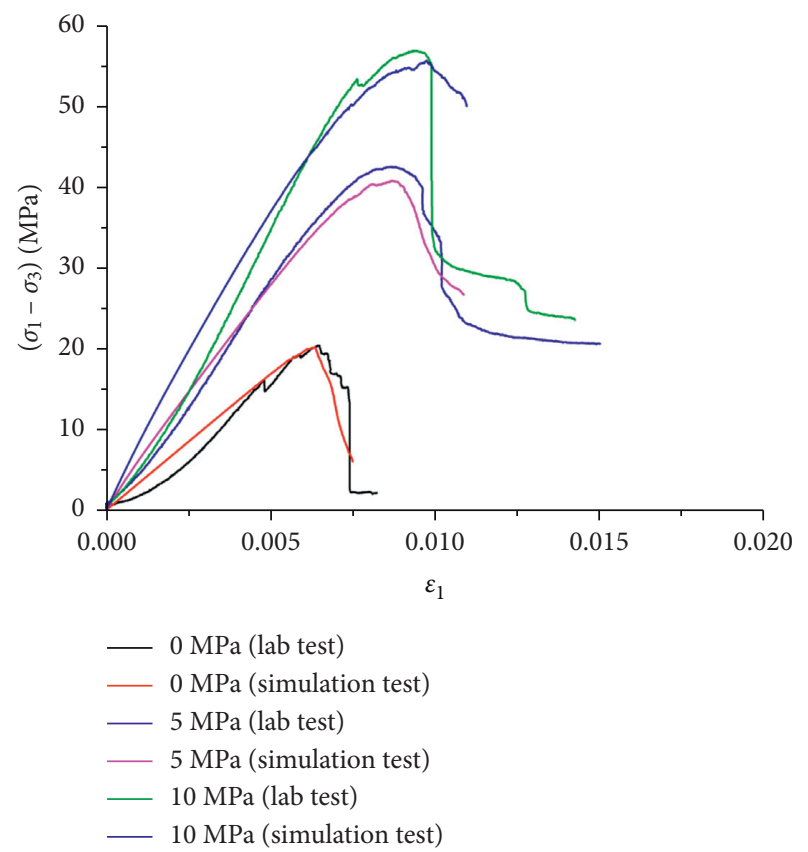

Figure 3: Comparison of simulating stress-strain curves and lab test curves (the loading rate of $0.02 \mathrm{~m} / \mathrm{s}$ ). Symbol $\sigma_{3}$ represents the confining pressure.

same time interval can be approximately equivalent to the measurement of AE activities [37]. This not only visualizes the study of AE characteristics through numerical simulation method but also eliminates the influence of friction-type acoustic emission. Since the purpose of numerical simulation is to study the basic mechanical properties of coal specimen subjected to cyclic loading, the peak stress of cyclic loading can be set at a higher level. This can accelerate the failure process of coal specimen and improve the computing efficiency. In this paper, cyclic loading is loaded according to the triangular waveform.
TABle 1: The meso-parameters in the model.

\begin{tabular}{lc}
\hline Parameter & Value \\
\hline fric & 0.0 \\
emod & $2.5 e 9$ \\
kratio & 1.0 \\
dp_nratio & 0.8 \\
dp_sratio & 0.8 \\
pb_ten & $5.0 e 6$ \\
pb_coh & $25.0 e 6$ \\
pb_fa & 0.0 \\
pb_emod & $1.0 e 9$ \\
pb_kratio & 1.0 \\
\hline
\end{tabular}

\subsection{Influence of the Confining Pressure on Coal Specimen Subjected to Cyclic Loading}

3.1.1. Stress-Strain Characteristics. In order to study the influence of confining pressure on the mechanical properties of coal specimen subjected to cyclic loading, the peak and valley stress of cyclic loading are fixed in the simulation test. The detailed test conditions and results are shown in Table 3, and the stress-strain curves and failure modes of coal specimen are shown in Figure 4.

Under the uniaxial stress state, the coal specimen was destroyed at the 4th cycle, and 656,539 time-steps were spent. Under the confining pressure of $5 \mathrm{MPa}$, the coal specimen was destroyed at the 20th cycle, and 4,219,657 time-steps were spent. Under the confining pressure of $10 \mathrm{MPa}$, the coal specimen was destroyed at the 38th cycle, and 11,715,047 time-steps were spent. The above part shows that when the peak and valley stress levels of cyclic loading are fixed, the higher the confining pressure, the more the cycle number and the testing time-step number. So, the confining pressure has a significant influence on the failure process of coal specimen subjected to cyclic loading; and with the increase in confining pressure, the cycle number and time-step number significantly increases.

3.1.2. Failure Mode. From Figure 4, the failure mode of cyclically loaded coal specimen under uniaxial stress state is significantly different from that under the confining pressures of 5 and $10 \mathrm{MPa}$. However, under the latter two confining pressures, there is little difference in the failure mode. Under uniaxial stress state, the main fractured plane of coal specimen is singly inclined, caused by the shear stress; besides, there are several tensile failures parallel to the axial direction of coal specimen near the main fractured plane. In other words, under uniaxial cyclic loading, the shear failure plays a dominant role in the final failure of coal specimen, and the tensile failure is only auxiliary. But, under the confining pressure of 5 and $10 \mathrm{MPa}$, the coal specimens are both in the form of dispersion failure, and there is no main fractured plane. So, the confining pressure is an important factor influencing the failure mode of coal specimen subjected to cyclic loading.

3.1.3. AE Characteristics. Figure 5 shows the AE counts and axial stress versus time-step curves of coal specimen subjected to cyclic loading under the confining pressure of 0,5 , 
TABLE 2: Comparison of peak strength and strain at the peak stress point in the simulation test and lab test.

\begin{tabular}{|c|c|c|c|c|c|c|}
\hline \multirow{2}{*}{ Confining pressure (MPa) } & \multicolumn{3}{|c|}{ Peak strength $(\mathrm{MPa})$} & \multicolumn{3}{|c|}{ Axial strain at the stress peak point } \\
\hline & Lab test & Simulation test & Error $(\%)$ & Lab test & Simulation test & Error (\%) \\
\hline 0 & 19.09 & 19.66 & 2.99 & 0.005964260 & 0.006321368 & 5.99 \\
\hline 5 & 41.54 & 40.82 & 1.73 & 0.008683106 & 0.008711012 & 3.21 \\
\hline 10 & 57.47 & 55.62 & 3.22 & 0.009213872 & 0.009741279 & 5.72 \\
\hline
\end{tabular}

TABLE 3: Test conditions and results of coal specimen subjected to cyclic loading (the loading-unloading rate of $0.03 \mathrm{~m} / \mathrm{s}$ ).

\begin{tabular}{lcccc}
\hline Scheme number & Confining pressure (MPa) & Stress cycle interval (corresponding to peak strength) & Cycle number & Time-step \\
\hline 1 & 0 & $0.5 \sim 0.95$ & 4 \\
2 & 5 & $0.5 \sim 0.95$ & 20 & $4,219,657$ \\
3 & 10 & $0.5 \sim 0.95$ & 38 & $11,715,047$ \\
\hline
\end{tabular}

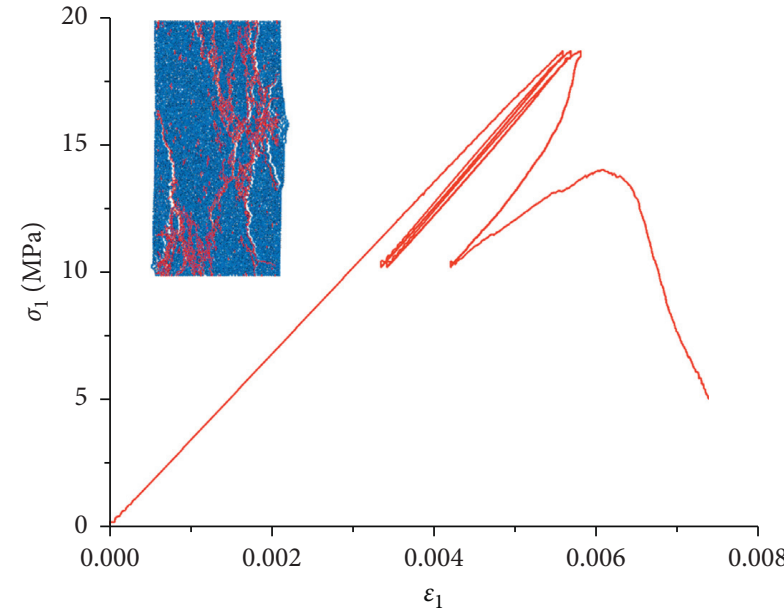

(a)

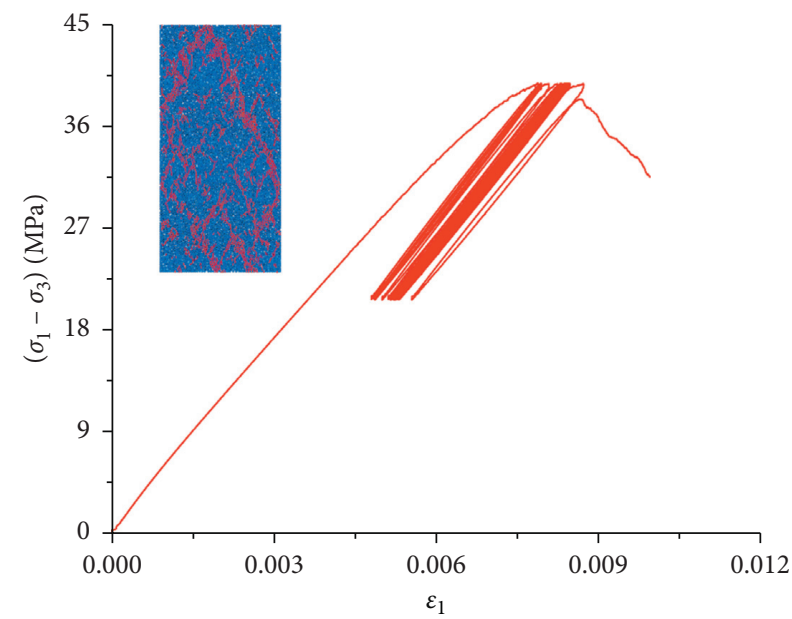

(b)

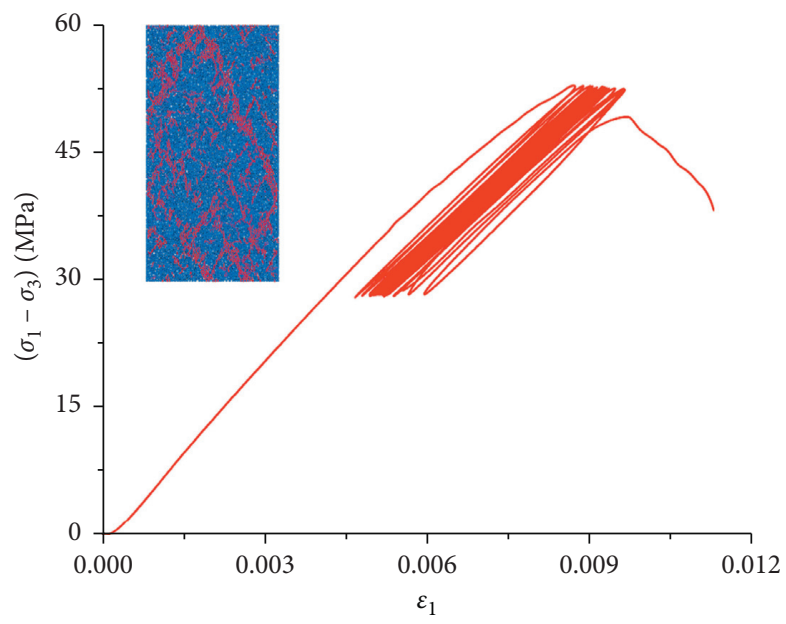

(c)

Figure 4: The axial stress- strain curves under different confining pressures: (a) $0 \mathrm{MPa}$, (b) $5 \mathrm{MPa}$, and (c) $10 \mathrm{MPa}$.

and $10 \mathrm{MPa}$, respectively. And count the AE activities every 10,000 time-steps. From Figure 5(a), the AE activities are very obvious in each loading-unloading cycle. Besides, there are few AE activities in the unloading phases of cycles 1 and 2 , but a large number of AE activities occur in the unloading phase of the 3rd cycle, and then the coal specimen was destroyed in the 4 th cycle. The above shows that when a large number of AE activities occur during the unloading stage in some cycle, it indicates that the coal specimen is about to be destroyed. From Figures 5(b) and 5(c), when the coal specimen is destroyed after many cycles, the AE activity is very little at each cycle before failure and presents a three- 


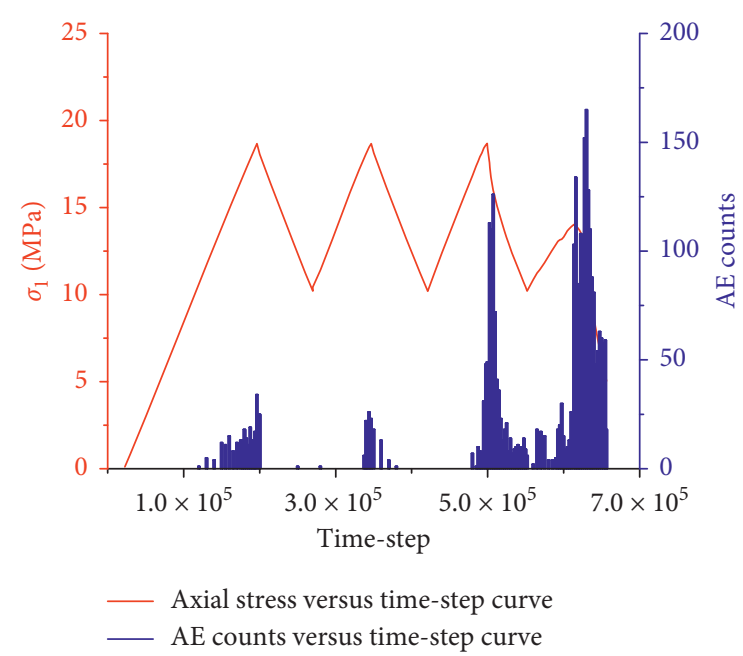

(a)

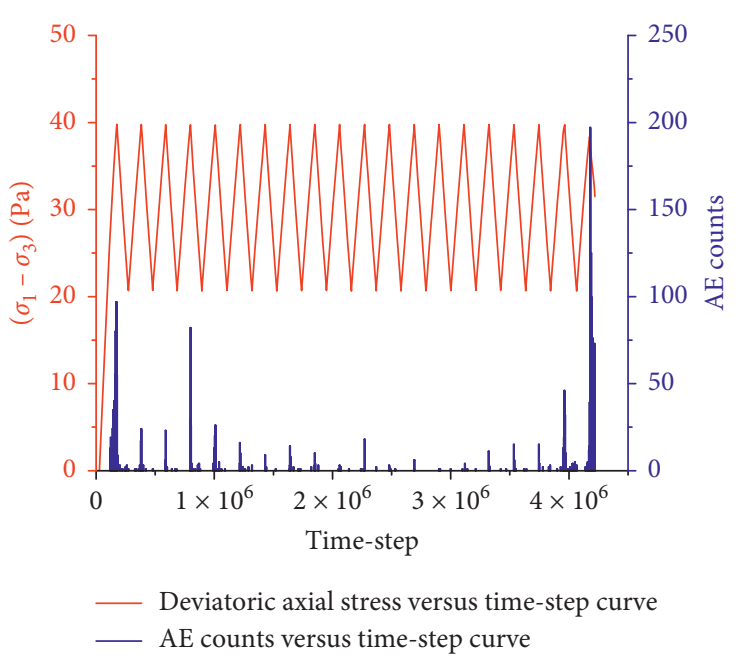

(b)

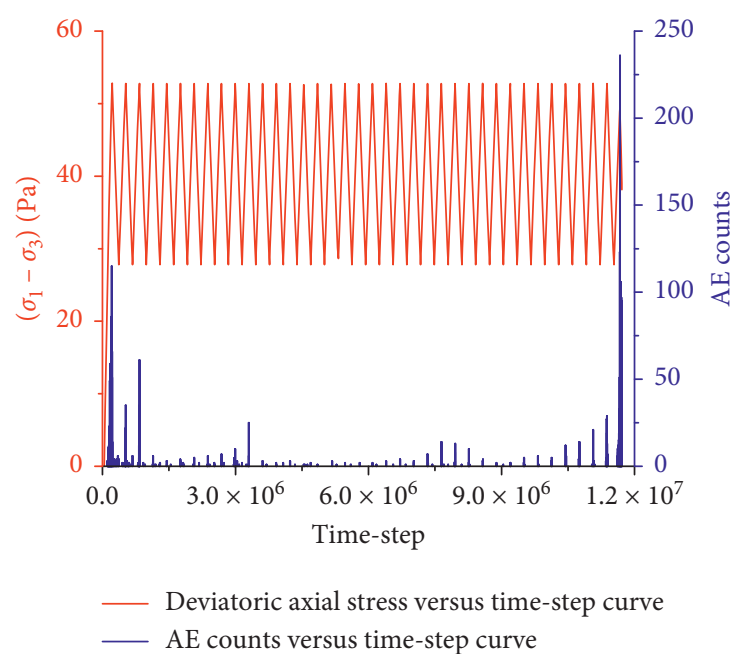

(c)

Figure 5: AE counts and axial stress versus time-step curves under different confining pressures: (a) $0 \mathrm{MPa}$, (b) $5 \mathrm{MPa}$, and (c) $10 \mathrm{MPa}$.

phase evolution law, namely, initial, relatively quiet, and active phases. In the initial phase, the AE activities decrease with the increase in cycle number. In the relatively quiet phase, the AE activities remain at a low level with the increase in cycle number. In the active phase, the AE activities become more and more intense with the cycle number and reach the maximum when the coal specimen is destroyed. Moreover, Figure 5 also shows that a large number of $\mathrm{AE}$ activities mainly occur at the high-stress stage of cyclic loading, and there are almost no AE activities at the lowstress stage (except when the coal specimen is about to be destroyed).

Figure 6shows the cumulative AE count curves per cycle before specimen failure under the confining pressure of 0 , 5 , and $10 \mathrm{MPa}$, respectively. In the 1 st cycle, the cumulative AE counts are 255,833 , and 1456 , respectively. The above shows that under the same stress level, the higher the confining pressure, the greater the cumulative AE counts at the 1st cycle. That is, the higher the confining pressure, the more the fractures occurred in the coal specimen at the 1 st cycle. However, at a cycle before coal specimen failure, the cumulative AE counts are 870, 255, and 112, respectively. This shows that the lower the confining pressure, the greater the precursory cyclic cumulative AE counts of coal specimen failure. On the whole, with the increase in the confining pressure, the cumulative AE counts at the 1st cycle tend to increase and the cumulative AE counts at a cycle before failure tend to decrease. In addition, with the increase in confining pressure, the final cycle number is obviously different. So, the confining pressure has a significant influence on the cyclic cumulative AE counts and the final cycle number of coal specimen subjected to cyclic loading.

In order to study the evolution law of $\mathrm{AE}$ counts with the cycle number, the ratio of the maximum AE counts in some cycle to the loudest $\mathrm{AE}$ counts in the 1st cycle is defined as the $\mathrm{AE}$ ratio, $K$. The equation is as follows:

$$
K=\frac{A_{i}}{A_{1}},
$$




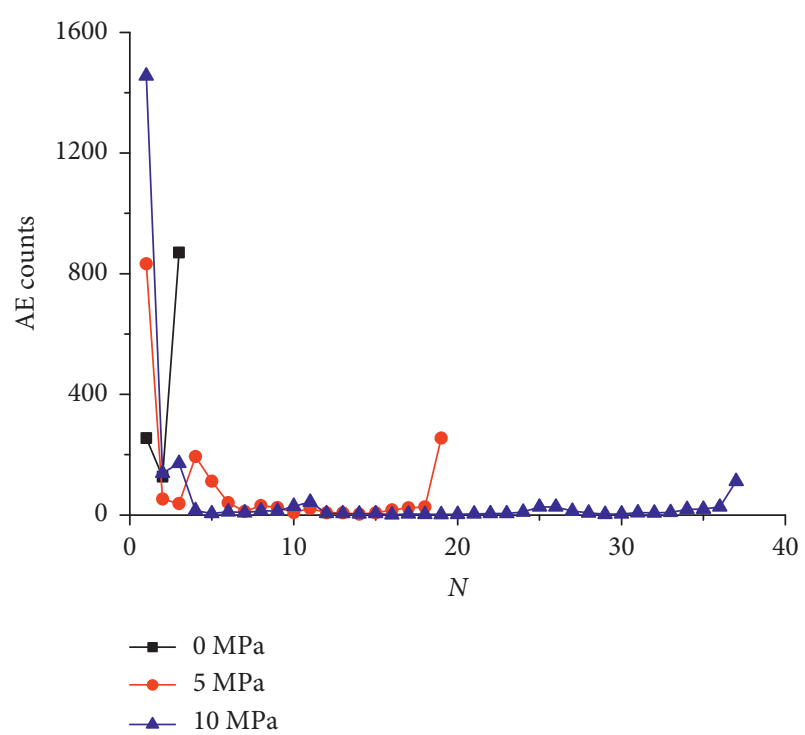

Figure 6: Cumulative AE count curves per cycle under different confining pressures.

where $A_{1}$ is the maximum $\mathrm{AE}$ counts in the 1 st cycle, and $A_{i}$ is the peak AE counts in the $i$-th cycle.

Figure 7 shows the AE ratio versus the cycle number curves under the confining pressures of 0,5 , and $10 \mathrm{MPa}$, respectively. At the same stress level, the $\mathrm{AE}$ ratio tends to decrease with the increase in confining pressure.

\subsection{Influence of the Loading-Unloading Rate of Cyclic Loading on Coal Specimen}

3.2.1. Stress-Strain Characteristics. Taking uniaxial condition as an example, the influence of cyclic loading-unloading rate on coal specimen failure is studied, and the loading-unloading rates are $0.02,0.03$, and $0.04 \mathrm{~m} / \mathrm{s}$, respectively. The peak stress of cyclic loading is set to $18.18 \mathrm{MPa}$ ( $92.5 \%$ of the conventional compression strength of coal specimen), and the valley stress is set to $10 \mathrm{MPa}$. Table 4 lists the test conditions and results. Figure 8 shows the stress-strain curves and failure modes of coal specimen subjected to cyclic loading with the three loading-unloading rates.

From Table 4 and Figure 8, under the loading-unloading rate of $0.02 \mathrm{~m} / \mathrm{s}$, the coal specimen was destroyed at the $12 \mathrm{th}$ cycle, and the 2,624,379 time-steps were spent; under the loading-unloading rate of $0.03 \mathrm{~m} / \mathrm{s}$, the coal specimen was also destroyed at the 12th cycle, and the 1,837,979 time-steps were spent; under the loading-unloading rate of $0.04 \mathrm{~m} / \mathrm{s}$, the coal specimen was destroyed at the 13th cycle, and the $1,534,179$ time-steps were spent. This shows that the loading-unloading rate of cyclic loading has some influence on the failure process of coal specimen. Although the coal specimen was destroyed at the 12th cycle under both the loading-unloading rates of 0.02 and $0.03 \mathrm{~m} / \mathrm{s}$, the peak stress of coal specimen in the failure cycle is higher under the latter loading-unloading rate. The above shows that when other conditions are the same, the faster the loading-unloading rate, the fewer the failure time-steps; however, with the increase in the loading-unloading rate, the cycle number tends to increase slowly.

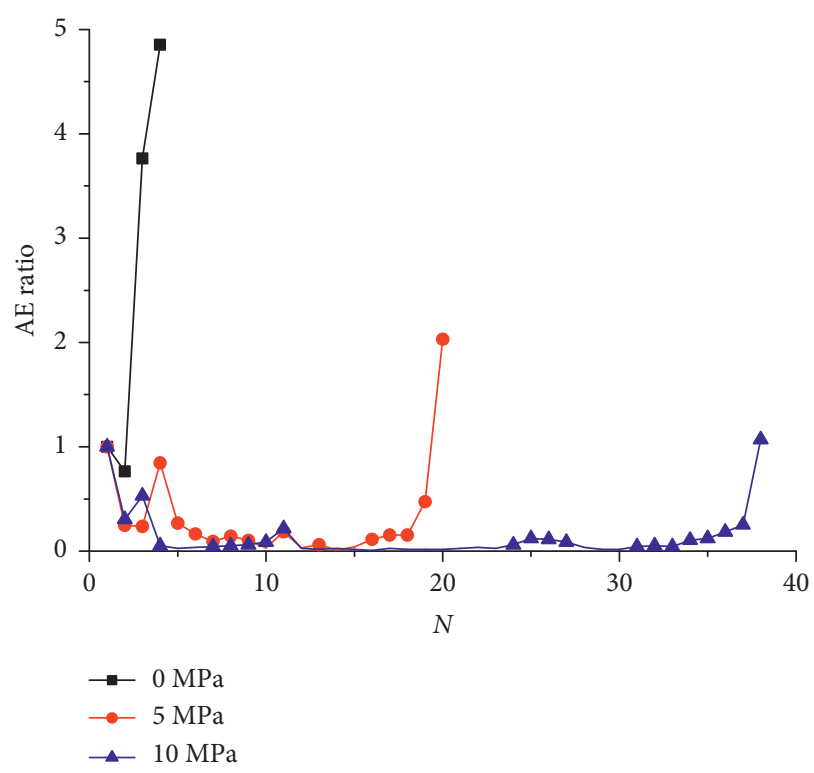

FIgURE 7: AE ratio versus cycle number curves.

3.2.2. Failure Mode. From Figure 8 , under the uniaxial cyclic loading-unloading rates of $0.02,0.03$, and $0.04 \mathrm{~m} / \mathrm{s}$, respectively, the failure mode of coal specimen has little difference. The main fractured plane of coal specimen is singly inclined, caused by the shear stress; besides, there are several tensile failures parallel to the axial direction of coal specimen near the main fractured plane. That is, the shear failure plays a dominant role in the final failure of coal specimen, and the tensile failure is only auxiliary. So, under uniaxial stress state, the cyclic loading-unloading rate has little influence on the failure mode of coal specimen.

3.2.3. AE Characteristics. Figure 9 shows the AE counts and axial stress versus time-step curves of coal specimen subjected to cyclic loading in the loading-unloading rate of 0.02 , 0.03 , and $0.04 \mathrm{~m} / \mathrm{s}$, respectively. The $\mathrm{AE}$ counts present a three-phase evolution law, namely, initial, relatively quiet, and active phases. The AE activities are most frequent in the failure cycle. However, there are almost no AE activities at the unloading or low-stress stage before coal specimen failure. In addition, in several cycles before the failure of coal specimen, the AE activities increase gradually with the cycle number, which can be used as a precursor of coal specimen failure.

Figure 10 shows the cumulative $\mathrm{AE}$ count curves per cycle before specimen failure under the loading-unloading rates of $0.02,0.03$, and $0.04 \mathrm{~m} / \mathrm{s}$, respectively. At the same stress level, the loading-unloading rate has some influence on the cyclic cumulative AE counts, but not obvious. Especially, at the first four cycles, the cumulative AE counts per cycle have little difference under the three loading-unloading rates. Then, with the increase in the cycle number, the cumulative $\mathrm{AE}$ counts per cycle are gradually different. Besides, with the increase in the difference of loadingunloading rate, the cumulative $\mathrm{AE}$ counts per cycle and the final cycle number are also gradually different. The above 
TABLE 4: Test conditions and results of coal specimen subjected to cyclic loading.

\begin{tabular}{|c|c|c|c|c|c|}
\hline Scheme number & Valley stress $(\mathrm{MPa})$ & Peak stress $(\mathrm{MPa})$ & Loading-unloading rate $\left(\mathrm{m} \cdot \mathrm{s}^{-1}\right)$ & Cycle number & Time-step \\
\hline 1 & 10 & 18.18 & 0.02 & 12 & $2,624,379$ \\
\hline 2 & 10 & 18.18 & 0.03 & 12 & $1,837,979$ \\
\hline 3 & 10 & 18.18 & 0.04 & 13 & $1,534,179$ \\
\hline
\end{tabular}

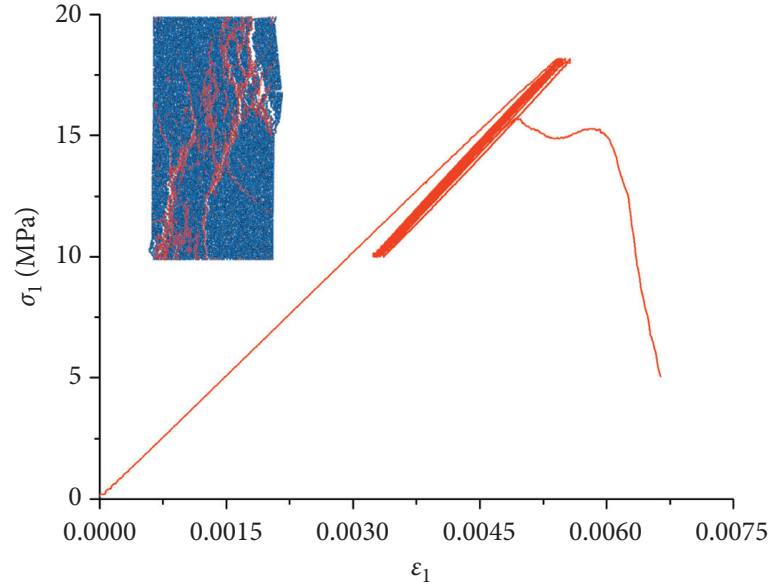

(a)

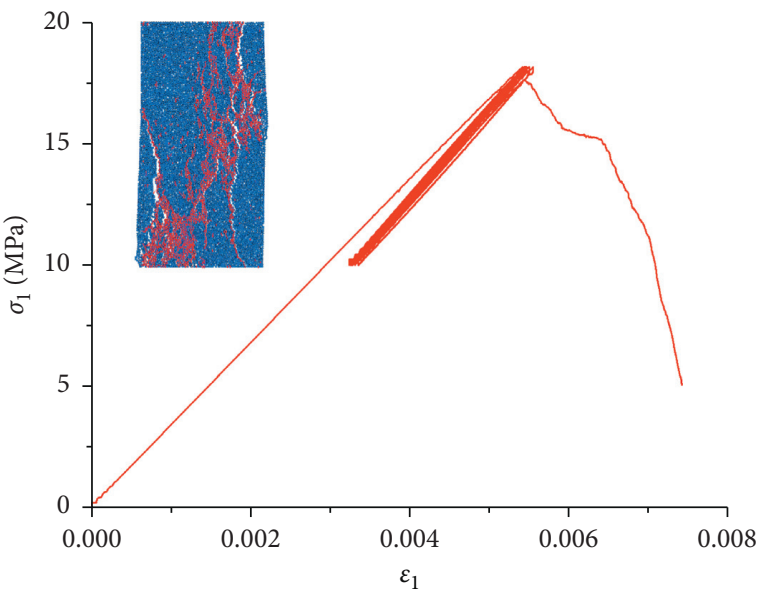

(b)

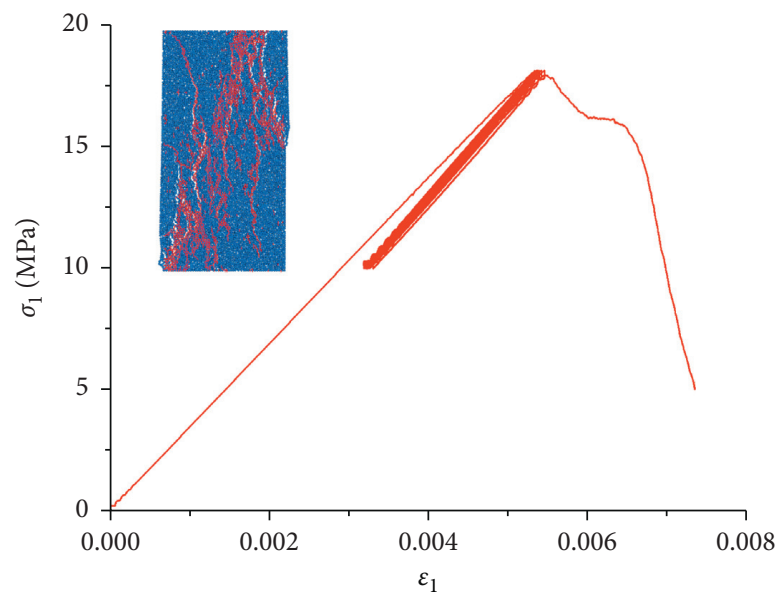

(c)

Figure 8: The axial stress- strain curves under different loading-unloading rates: (a) $0.02 \mathrm{~m} / \mathrm{s}$, (b) $0.03 \mathrm{~m} / \mathrm{s}$, and (c) $0.04 \mathrm{~m} / \mathrm{s}$.

shows that the cyclic loading-unloading rates with a little difference have little influence on the cyclic cumulative $\mathrm{AE}$ counts and the final cycle number.

Figure 11 shows the $\mathrm{AE}$ ratio versus the cycle number curves under the loading-unloading rates of $0.02,0.03$, and $0.04 \mathrm{~m} / \mathrm{s}$, respectively, and these curves clearly reflect the three-phase evolution characteristics of AE activities. Each micro-fracture in the coal specimen is defined as an AE event and corresponds to a certain irreversible strain as well, so the evolution of $\mathrm{AE}$ ratio can also better reflect the different phases of coal specimen failure subjected to cyclic loading. When the AE ratio decreases with the cycle number, it indicates that the coal specimen is in the initial phase of the failure. When the $\mathrm{AE}$ ratio keeps stable with the cycle number, the coal specimen is in the constant phase of the failure. When the AE ratio increases with the cycle number, the coal specimen is in the acceleration phase of the failure.

\subsection{Influence of the Valley Stress of Cyclic Loading on Coal Specimen}

3.3.1. Stress-Strain Characteristics. Under the loadingunloading rate of $0.03 \mathrm{~m} / \mathrm{s}$, the influence of cyclic loading valley stress on coal specimen failure is studied. The valley stresses of cyclic loading are 6, 8, and $10 \mathrm{MPa}$, respectively, and the peak stress is set to $18.18 \mathrm{MPa}(92.5 \%$ of the conventional compression strength of coal specimen). Table 5 lists the test conditions and results. Figure 12 shows the stress-strain curves and failure modes of coal specimen subjected to cyclic loading with the three valley stresses. 


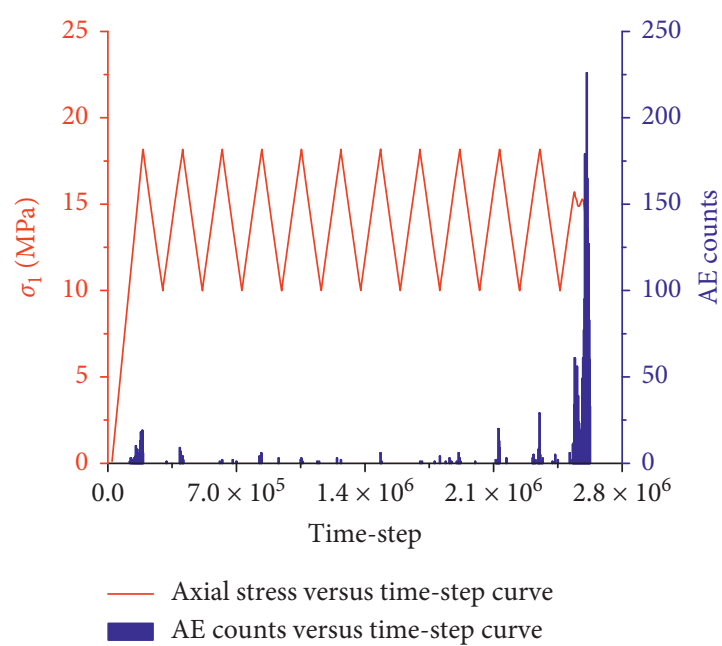

(a)

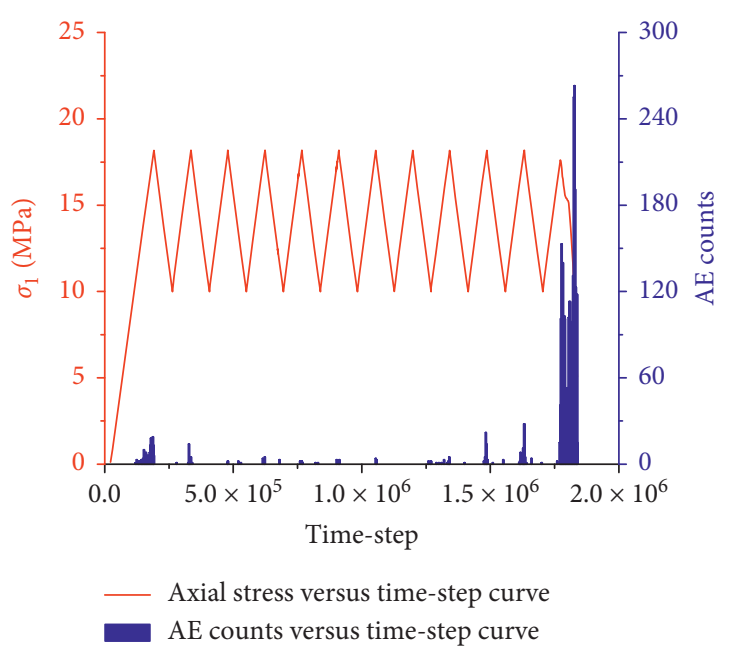

(b)

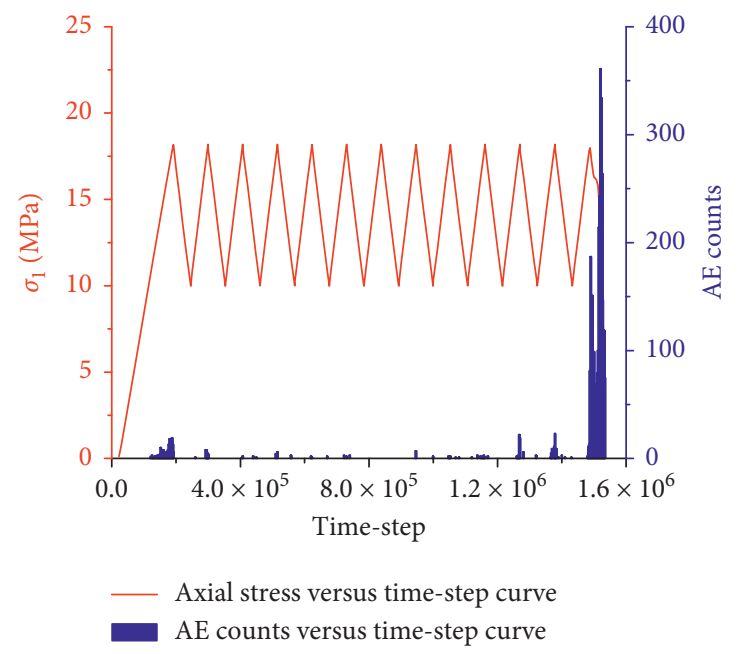

(c)

FIGURE 9: AE counts and axial stress versus time-step curves under different loading-unloading rates: (a) $0.02 \mathrm{~m} / \mathrm{s}$, (b) $0.03 \mathrm{~m} / \mathrm{s}$, and (c) $0.04 \mathrm{~m} / \mathrm{s}$.

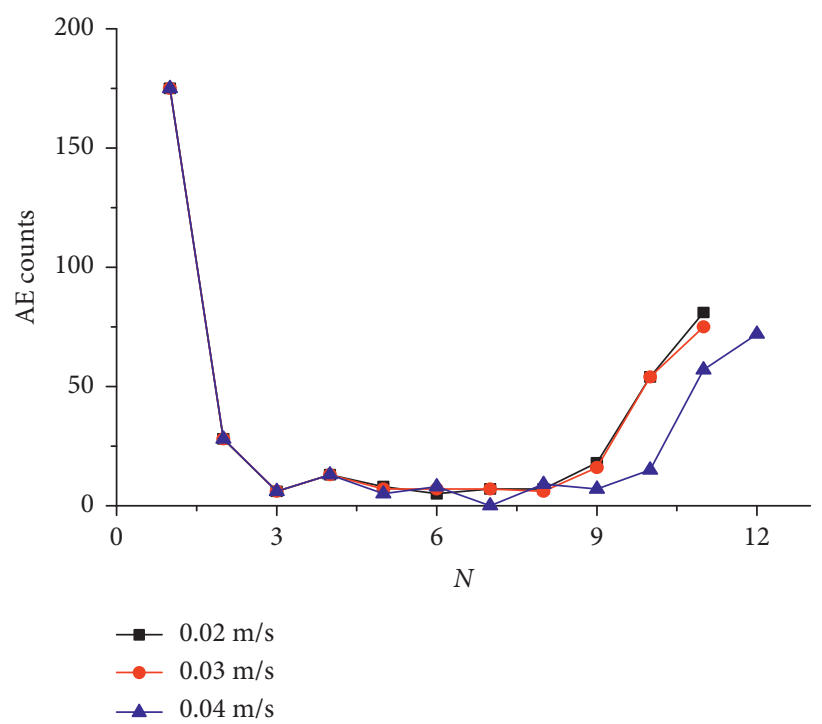

Figure 10: Cumulative AE counts curves per cycle under different loading-unloading rates. 


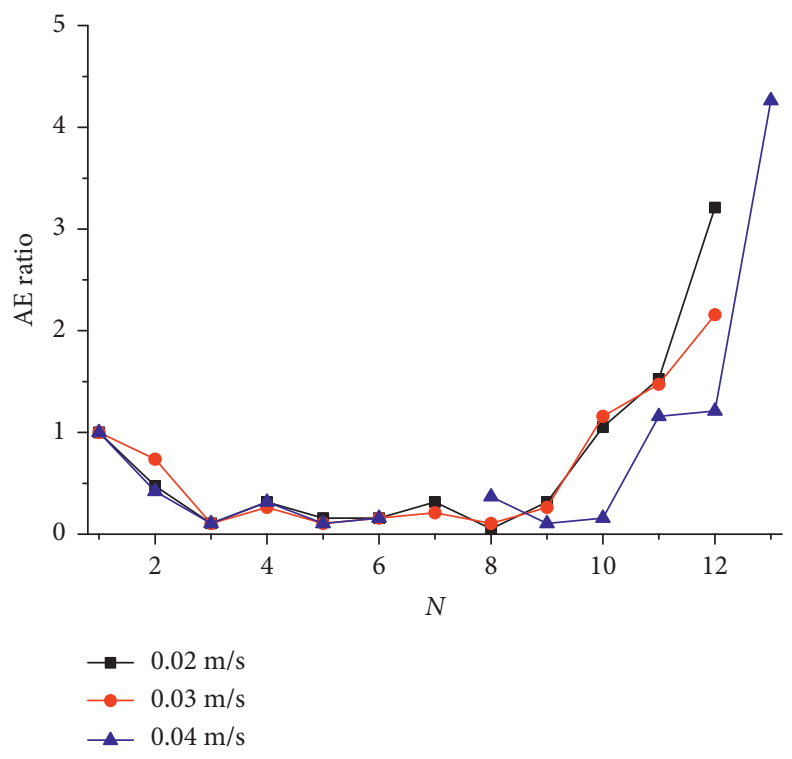

Figure 11: AE ratio versus cycle number curves.

TABle 5: Test conditions and results of coal specimen subjected to cyclic loading (the loading-unloading rate of $0.03 \mathrm{~m} / \mathrm{s}$ ).

\begin{tabular}{lccccc}
\hline Scheme number & Valley stress $(\mathrm{MPa})$ & Peak stress $(\mathrm{MPa})$ & Stress amplitude $(\mathrm{MPa})$ & Cycle number & Time-step \\
\hline 1 & 6 & 18.18 & 12.18 & 7 & $1,573,079$ \\
2 & 8 & 18.18 & 10.18 & 10 & $1,897,379$ \\
3 & 10 & 18.18 & 8.18 & 12 & $1,837,979$ \\
\hline
\end{tabular}

From Table 5 and Figure 12, when the valley stress of cyclic loading is $6 \mathrm{MPa}$, the coal specimen was destroyed at the 7th cycle, and the 1,573,079 time-steps were spent; when the valley stress of cyclic loading is $8 \mathrm{MPa}$, the coal specimen was destroyed at the 10th cycle, and the 1,897,379 time-steps were spent; when the valley stress of cyclic loading is $10 \mathrm{MPa}$, the coal specimen was destroyed at the 12th cycle, and the $1,837,979$ time-steps were spent. The above shows that when the peak stress of uniaxial cyclic loading are fixed, with the decrease in the valley stress, the cycle number of coal specimen failure gradually reduces; that is, the damage increases in each cycle.

3.3.2. Failure Mode. From Figure 12, under the uniaxial cyclic loading with the valley stresses of 6,8 , and $10 \mathrm{MPa}$, respectively, the failure mode of coal specimen has little difference. The main fractured plane of coal specimen is singly inclined, caused by the shear stress; besides, there are several tensile failures parallel to the axial direction of coal specimen near the main fractured plane. That is, the shear failure plays a dominant role in the final failure of coal specimen, and the tensile failure is only auxiliary. So, under uniaxial stress state, the valley stress of cyclic loading has little influence on the failure mode of coal specimen.

3.3.3. AE Characteristics. Figure 13 shows the AE counts and axial stress versus time-step curves of coal specimen subjected to cyclic loading with the three valley stresses. The AE counts present a three-phase evolution law, namely, initial, relatively quiet, and active phases. The AE activities are most frequent in the failure cycle. In addition, there are almost no $\mathrm{AE}$ activities at the unloading or low-stress stage of cyclic loading before coal specimen failure.

Figure 14 shows the cumulative AE count curves per cycle before specimen failure under the valley stresses of 6,8 , and $10 \mathrm{MPa}$, respectively. At the same loading-unloading rate, in the 1st cycle, the cyclic cumulative $\mathrm{AE}$ counts have a little difference under the three valley stresses. With increase in the number of cycles, the difference of cumulative AE counts per cycle increases. Besides, with the increase in the difference of valley stresses, the final cycle number is also obviously different. Especially, in the relatively quiet phase, the lower the valley stress, the greater the cumulative AE counts per cycle. That is, the lower the valley stress, the more the fractures occurred in the coal specimen in the relatively quiet phase. The above shows that the valley stress of cyclic loading has little influence on the cumulative AE counts in the 1st cycle but has a relatively significant influence on the cumulative $\mathrm{AE}$ counts in the subsequent cycles and the final cycle number.

Figure 15 shows the AE ratio versus the cycle number curves in the three valley stresses. The curve clearly reflects the three-phase evolution characteristics of $\mathrm{AE}$ activities and different stages of coal specimen failure subjected to cyclic loading.

\section{Damage Evolution of Coal Specimen Subjected to Cyclic Loading}

Damage refers to the progressive weakening of internal cohesion caused by the development of material micro- 


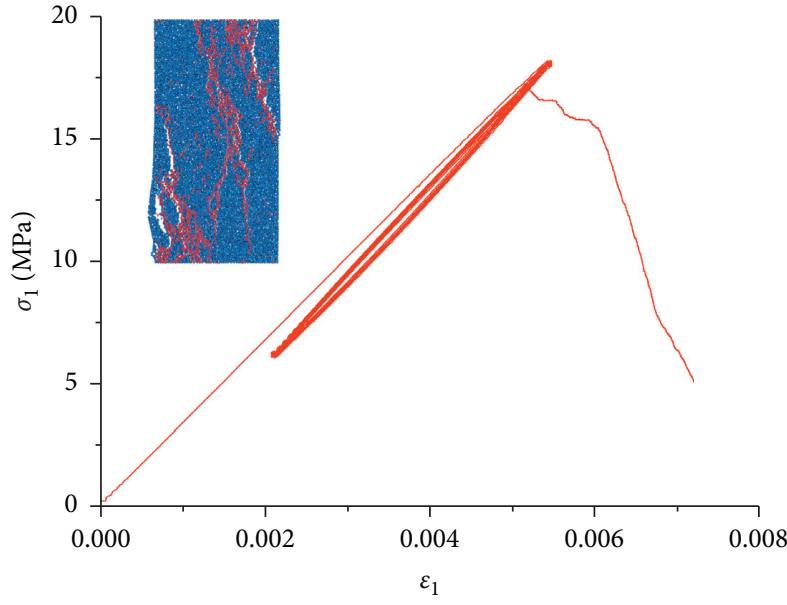

(a)

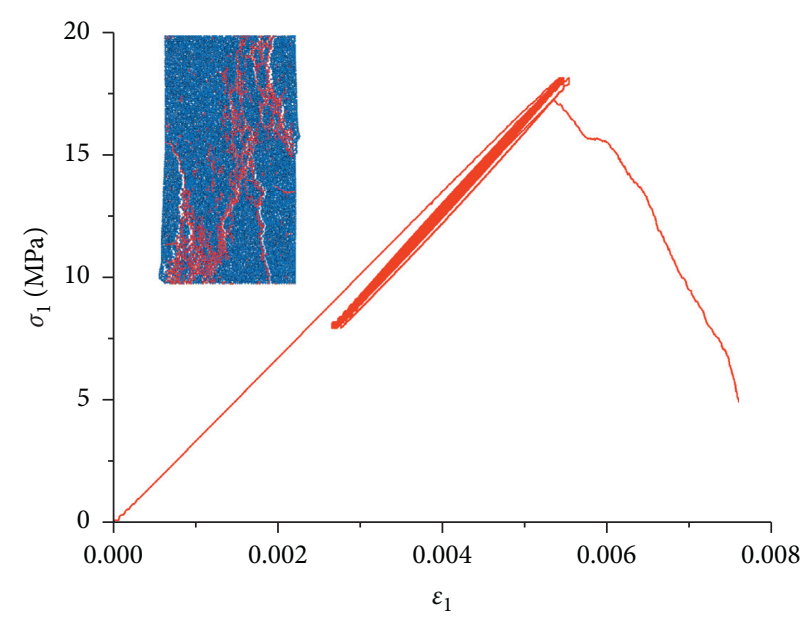

(b)

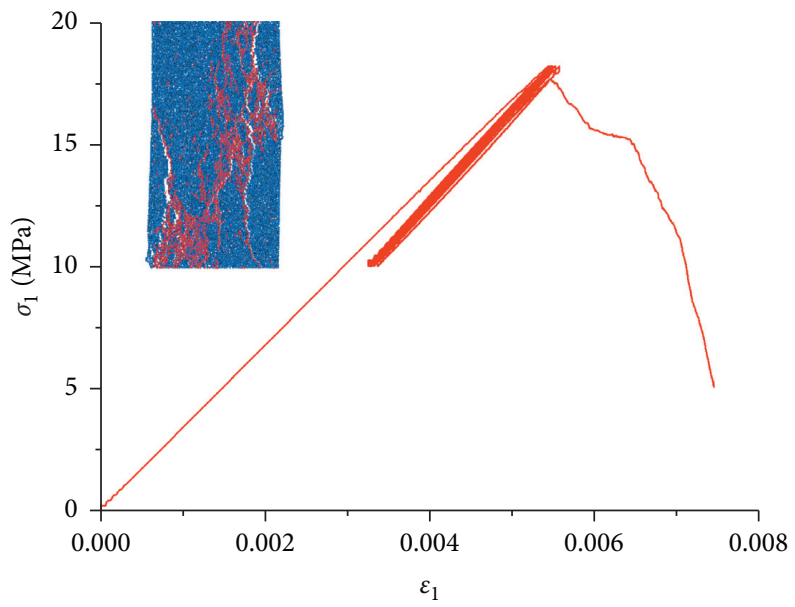

(c)

Figure 12: The axial stress- strain curves under different valley stresses: (a) 6 18.18 MPa, (b) 8 18.18 MPa, and (c) 10 18.18 MPa.

defects subjected to monotonic or repeated loading and finally leads to the failure of volume units [39]. Damage can change many properties of materials, such as the decrease of elastic modulus, ultrasonic velocity, and density. For damage, we must give a quantitative calculation method. Reasonable damage variables should have a clear physical meaning and easy to be measured and used in engineering. In this paper, the cumulative $\mathrm{AE}$ counting method is used to calculate the damage of coal specimen subjected to cyclic loading.

Xiao et al. [40] proposed a very concise equation for damage calculation. The equation is as follows:

$$
D=\frac{N}{N_{m}},
$$

where $N$ is the cumulative $\mathrm{AE}$ counts at the end of some cycle and $N_{m}$ is the cumulative $\mathrm{AE}$ counts at the specimen failure.

Because equation (3) cannot express the damage at some time-step in a cycle, the calculating damage is discontinuous by this method. In order to obtain the continuous damage value, here, the parameter " $N$ " is defined as the cumulative $\mathrm{AE}$ counts at some time-step.
Taking coal specimens subjected to cyclic loading with the confining pressures of 0,5 , and $10 \mathrm{MPa}$ as an example. Figure 16 shows the continuous damage evolution process of coal specimen subjected to cyclic loading. Figure 17 shows the damage curves of coal specimen subjected to cyclic loading at each cycle. Table 6 shows the number of fractured and unbroken contacts and their ratio at the peak stress point of specimen failure cycle under the three confining pressures.

From Figures 16 and 17, under the confining pressures of 0,5 , and $10 \mathrm{MPa}$, the damages at the 1 st cycle are 0.1634 , 0.4623 , and 0.5659 , respectively. This shows that the damage at the 1st cycle increases with the increase in confining pressure. On further analysis, the following conclusions can be obtained. Under the uniaxial stress state, coal specimen is destroyed only at the 4th cycle, and the damage almost linearly increases; under the confining pressures of 5 and $10 \mathrm{MPa}$, coal specimen is respectively destroyed at the 20th and 38th cycle, the damage presents the three-phase evolution law, namely, initial, steady, and accelerating phases. So, the confining pressure has a great influence on the damage evolution process of coal specimen subjected to 


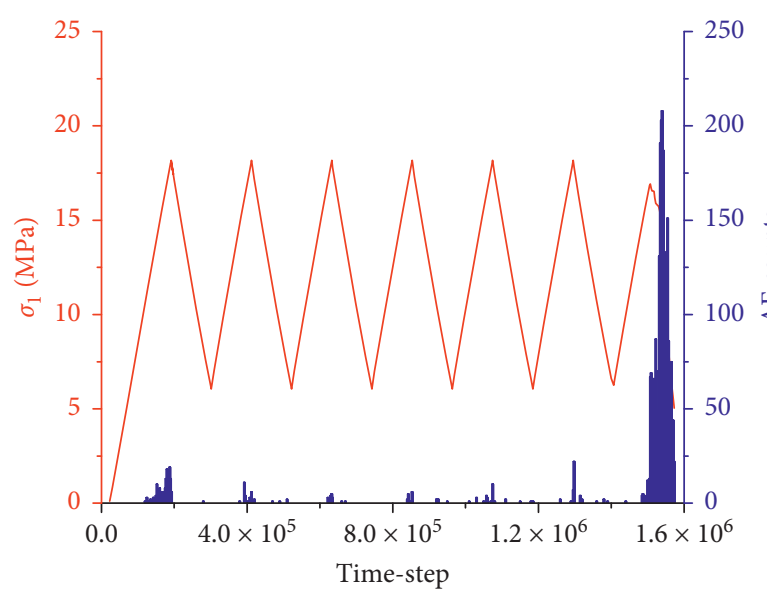

Axial stress versus time-step curve AE counts versus time-step curve

(a)

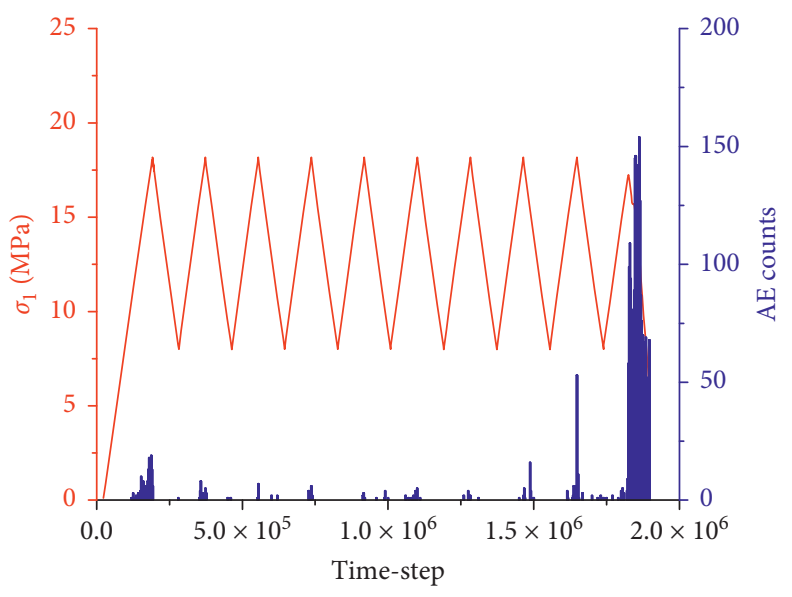

Axial stress versus time-step curve AE counts versus time-step curve

(b)

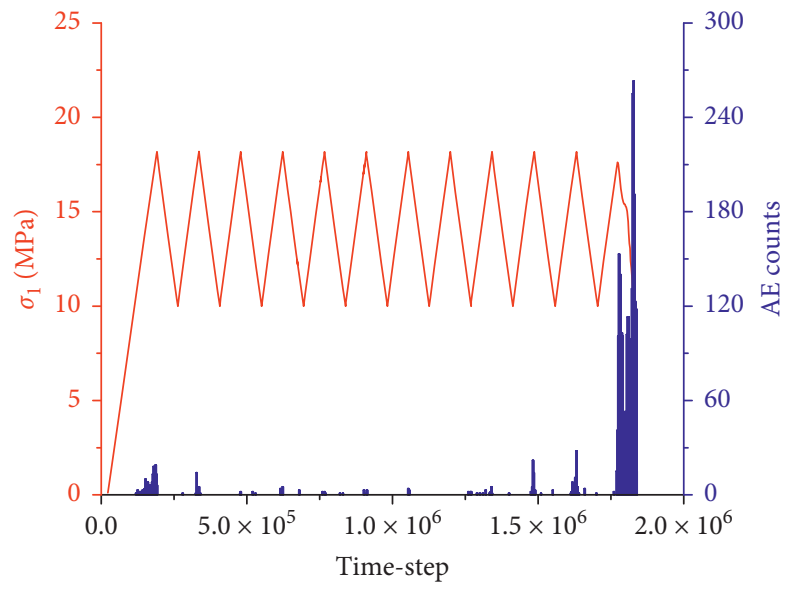

Axial stress versus time-step curve

AE counts versus time-step curve

(c)

FigURE 13: AE counts and axial stress versus time-step curves under different valley stresses: (a) 6 18.18 MPa, (b) $8 \sim 18.18 \mathrm{MPa}$, and (c) $10 \sim 18.18 \mathrm{MPa}$.

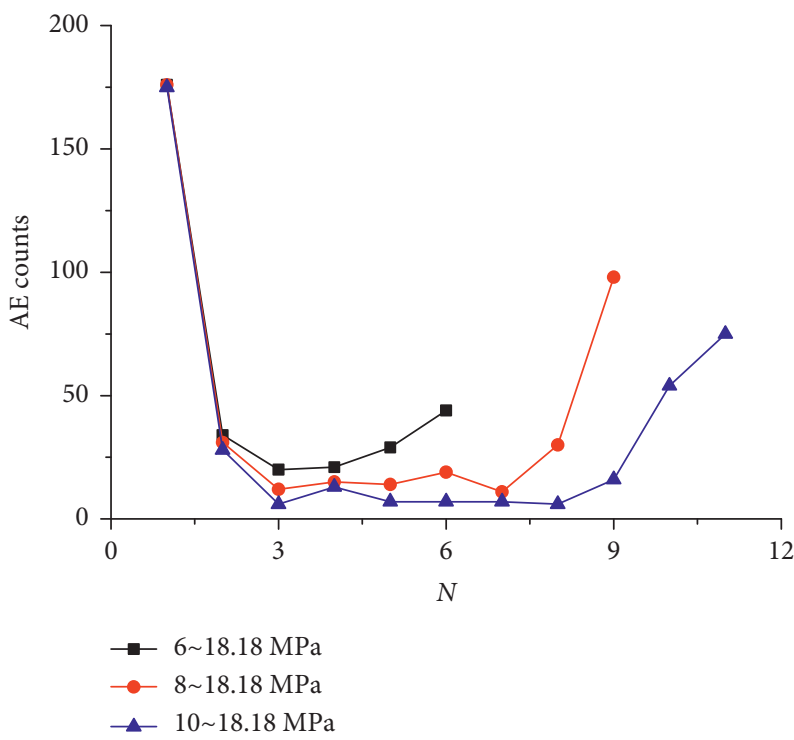

FIGURE 14: Cumulative AE count curves per cycle under different valley stresses. 


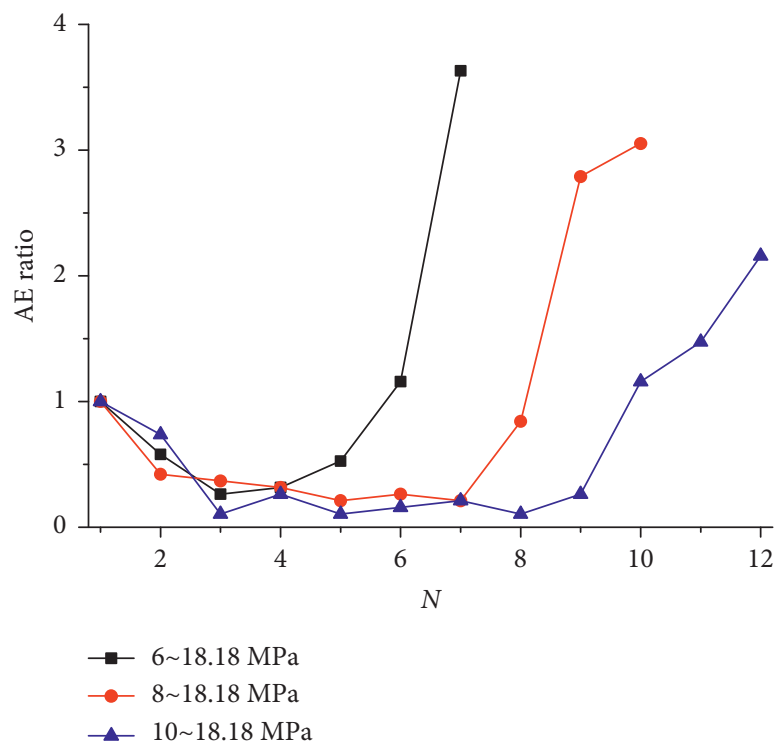

FIgURE 15: AE ratio versus cycle number curves.

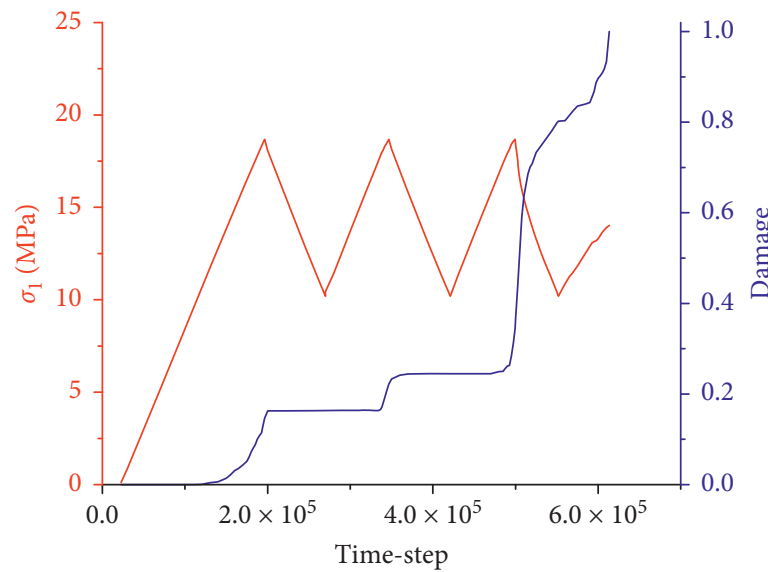

Axial stress versus time-step curve Damage versus time-step curve

(a)

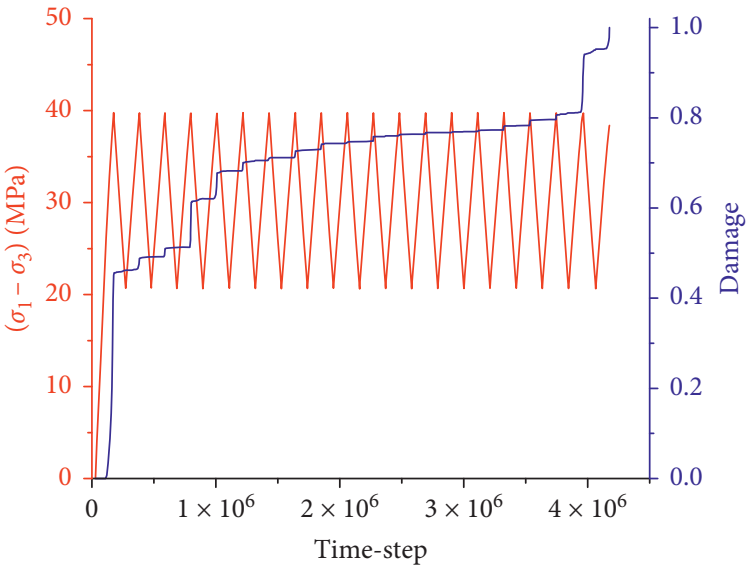

- Deviatoric axial stress versus time-step curve

_ Damage versus time-step curve

(b)

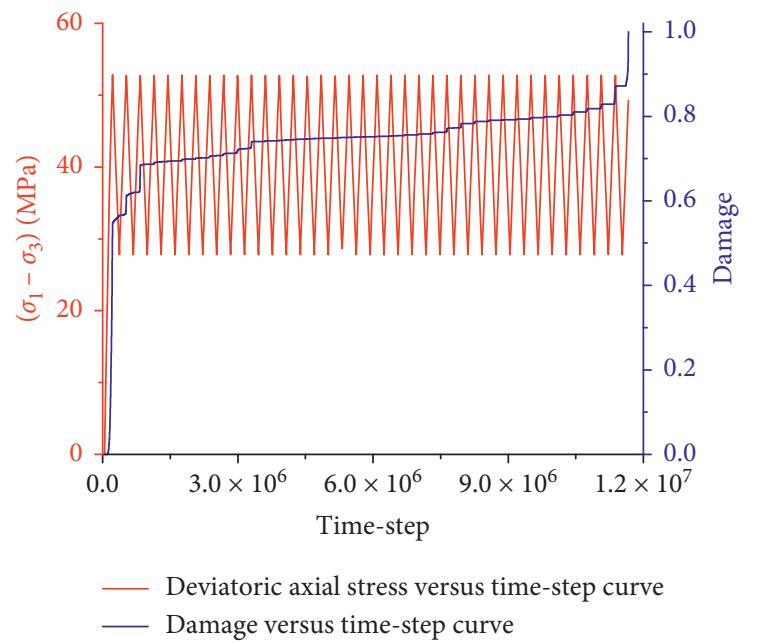

(c)

FIGURE 16: The damage evolution curves of coal specimen subjected to cyclic loading under the different confining pressures: (a) 0 MPa, (b) $5 \mathrm{MPa}$, and (c) $10 \mathrm{MPa}$. 


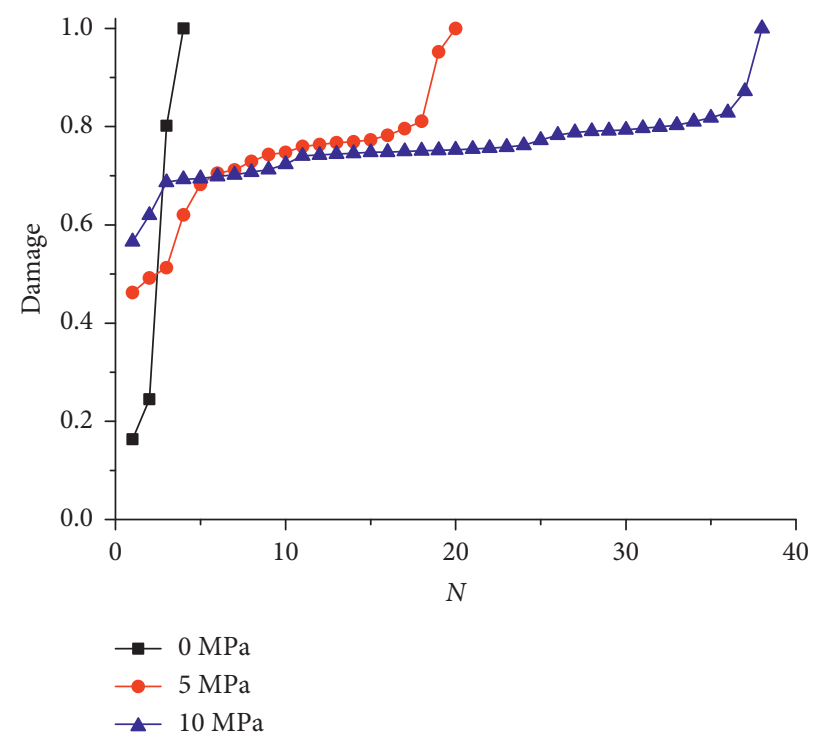

Figure 17: The damage curves of coal specimen subjected to cyclic loading at each cycle under the different confining pressures.

TABLE 6: Contact number of specimen at the peak stress point of failure cycle under the different confining pressures.

\begin{tabular}{|c|c|c|c|c|}
\hline Scheme number & Confining pressure (MPa) & Number of fractured contacts & Number of unbroken contacts & Ratio (\%) \\
\hline 1 & 0 & 1561 & 15,837 & 9.86 \\
\hline 2 & 5 & 1802 & 17,142 & 10.51 \\
\hline 3 & 10 & 2573 & 18,215 & 14.13 \\
\hline
\end{tabular}

cyclic loading. More importantly, the damage of coal specimen subjected to cyclic loading increases rapidly before forthcoming failure, so it is of great significance to use the AE monitoring technology to explore the precursory characteristics of coal specimen failure.

From Table 6, under the confining pressures of 0,5 , and $10 \mathrm{MPa}$, the ratio of fractured contacts to unbroken contacts are $9.86,10.51$, and 14.13 percent, respectively. A general trend is that this rate rises with the increase in the confining pressure. That is, the higher the confining pressure, the more broken the failed coal specimen subjected to cyclic loading. The above shows that the confining pressure has a large influence on the broken degree of coal specimen subjected to cyclic loading.

\section{Discussion}

At present, the $\mathrm{AE}$ characteristics of rock under cyclic loading have been widely studied, and many rich research results have also been obtained $[5,7,15,26,30-33]$. However, most of these achievements are based on the lab test and do not consider the discreteness of specimen and not fully study the failure mode of specimen. So, this paper studies the AE characteristics and failure mode of coal specimen under different confining pressures, loadingunloading rates, and valley stresses by numerical simulation.

In this paper, the numerical simulation results show that with the increase in confining pressure, the cycle number of coal specimen failure increases significantly; with the increase in the loading-unloading rate, the cycle number of coal specimen failure tends to increase slowly; the lower the valley stress, the less the cycle number of coal specimen failure. These results are consistent with that of the lab tests. Therefore, for some problems of rock mechanics subjected to cyclic loading difficult to be studied by the lab test, the numerical simulation method is a way to solve them. In addition, the numerical simulation results also show that the $\mathrm{AE}$ activities of coal specimen subjected to cyclic loading present a three-phase evolution law, namely, initial, relatively quiet, and active phases. The AE ratio proposed in this paper can well reflect these three phases. Because there are little or no $\mathrm{AE}$ activities in the relatively quiet phase, the Kaiser effect can be considered to play a leading role. Because $\mathrm{AE}$ activities become more and more intense in the active phase, the Felicity effect can be considered to play a dominant role. So, the failure of cyclically loaded coal specimen is the combined result of the two AE effects. Meanwhile, the appearance of Felicity effect can be used as a precursory index of specimen failure. For the failure mode and degree of coal specimen, the effect of confining pressure is very significant. Under uniaxial stress state, there is an inclined main fractured plane in coal specimen; however, under the confining pressures of 5 and $10 \mathrm{MPa}$, the coal specimen represents dispersion failure. Besides, under these three confining pressures, the ratios of fractured contacts to unbroken contacts are 9.86, 10.51, and 14.13 percent, respectively. It can be concluded that with the increase in confining pressure, the coal sample tends to be more broken.

In fact, the in situ rock masses generally consist of many types of rock; therefore, to study the AE characteristics of 
rock combination body subjected to cyclic loading is more helpful to solve the in situ rock engineering problems. In addition, in most cases, the in situ rock masses are subjected to noncyclic loading, sometimes dynamic loading; therefore, the rock engineering problems subjected to the two loadings also need to be further studied in the future. More importantly, to study the AE characteristics of rock subjected to cyclic loading is aimed at providing the reliable precursory indicator for predicting its damage and failure. So, it is more meaningful to study the nonlinear prediction method of rock failure based on the three-phase evolution law of $\mathrm{AE}$ activities under cyclic loading through the nonlinear theory. For example, the $\mathrm{AE}$ waveform signals obtained in the lab test are analyzed through the methods of wavelet and spectrum analysis and then to study the evolution law of discrete wavelet coefficient and main frequency in the loading process. If the mutation characteristics of the discrete wavelet coefficient and the main frequency at specimen failure can be determined, then the two indexes can be used as the precursory information to predict the specimen failure.

\section{Conclusions}

In this paper, the influence of confining pressure, loadingunloading rate, and valley stress on the $\mathrm{AE}$ characteristics and failure process of coal specimen subjected to cyclic loading is studied by using the PFC simulation software. The main conclusions are as follows:

(1) The cycle number of failed coal specimen subjected to cyclic loading is significantly influenced by the confining pressure, followed by the valley stress, and finally the loading-unloading rate. With the increase in confining pressure, the cycle number significantly increases; with the decrease in valley stress, the cycle number gradually reduces; and with the increase in loading-unloading rate, the cycle number tends to increase slowly.

(2) The failure mode of coal specimen subjected to cyclic loading is significantly influenced by the confining pressure. Under uniaxial stress state, the main fractured plane of coal specimen is singly inclined, caused by the shear stress; besides, there are several tensile failures parallel to the axial direction of coal specimen near the main fractured plane. Under the confining pressures of 5 and $10 \mathrm{MPa}$, the coal specimens are both in the form of dispersion failure and there is no main fractured plane. However, the loading-unloading rate and valley stress of cyclic loading has little influence on it.

(3) The AE counts of coal specimen subjected to cyclic loading is greatly influenced by the confining pressure and the valley stress. With the increase in the confining pressure, the cumulative $\mathrm{AE}$ counts at the 1st cycle tend to increase but decrease at a cycle before failure; with the decrease in the valley stress, the cumulative $\mathrm{AE}$ counts per cycle increase in the relatively quiet phase. However, the loadingunloading rate has a little influence on it.
(4) A large number of AE activities mainly occur at the high-stress stage of cyclic loading, and there are almost no $\mathrm{AE}$ activities at the low-stress stage before forthcoming failure of coal specimen. If a large number of $\mathrm{AE}$ activities occur during the unloading stage in some cycle, it indicates that the coal specimen is about to be destroyed.

(5) When the coal specimen is destroyed after many cycles, the AE activities present a three-phase evolution law, namely, initial, relatively quiet, and active phases. The AE ratio is proposed, and it is defined as the ratio of the maximum $\mathrm{AE}$ counts in some cycle to the loudest $\mathrm{AE}$ counts in the 1st cycle. The evolution of $\mathrm{AE}$ ratio can better reflect the different stages of coal specimen failure under cyclic loading.

(6) Under different confining pressures, the continuous damage evolution curves of coal specimen subjected to cyclic loading are obtained. Meanwhile, the influence of confining pressure on the broken degree of coal specimen subjected to cyclic loading is analyzed through the ratio of fractured contacts to unbroken contacts and shows that the higher the confining pressure, the more broken the failed coal specimen subjected to cyclic loading.

\section{Data Availability}

The data used to support the findings of this study are available from the corresponding author upon request.

\section{Conflicts of Interest}

The authors declare that they have no conflicts of interest.

\section{Acknowledgments}

This research was supported by the National Natural Science Foundation of China (Grant no. 51574156) and the Natural Science Innovation Foundation of Inner Mongolia University of Science and Technology (Grant no. 2019QDLB25).

\section{References}

[1] S. J. Chen, W. J. Guo, H. Zhou, B. Shen, and J. B. Liu, "Field investigation of long-term bearing capacity of strip coal pillars," International Journal of Rock Mechanics and Mining Sciences, vol. 70, pp. 109-114, 2014.

[2] P. Wang, L. S. Jiang, J. Q. Jiang, P. Q. Zheng, and W. Li, "Strata behaviors and rock burst inducing mechanism under the coupling effect of a hard, thick stratum and a normal fault," International Journal of Geomechanics, vol. 2018, no. 2, Article ID 04017135, p. 14, 2018.

[3] Z. J. Wen, S. L. Jing, Y. J. Jiang et al., "Study of the fracture law of overlying strata under water based on the flow-stressdamage model," Geofluids, vol. 2019, Article ID 3161852, 12 pages, 2019.

[4] E. Aker, D. Kühn, V. Vavryčuk, M. Soldal, and V. Oye, "Experimental investigation of acoustic emissions and their moment tensors in rock during failure," International Journal 
of Rock Mechanics and Mining Sciences, vol. 70, no. 3, pp. 286-295, 2014.

[5] Q. B. Meng, M. W. Zhang, L. J. Han, H. Pu, and T. Y. Nie, "Effects of acoustic emission and energy evolution of rock specimens under the uniaxial cyclic loading and unloading compression," Rock Mechanics and Rock Engineering, vol. 49, no. 10, pp. 3873-3886, 2016.

[6] E. J. Kaiser, A study of acoustic phenomena in tensile test, Ph.D. thesis, Technische Hochschule München, Munich, Germany, 1959.

[7] X. Wang, Z. J. Wen, Y. J. Jiang, and H. Huang, "Experimental study on mechanical and acoustic emission characteristics of rock-like material under non-uniformly distributed loads," Rock Mechanics and Rock Engineering, vol. 51, no. 3, pp. 729-745, 2018.

[8] X. G. Kong, E. Y. Wang, S. B. Hu, R. X. Shen, X. L. Li, and T. Q. Zhan, "Fractal characteristics and acoustic emission of coal containing methane in triaxial compression failure," Journal of Applied Geophysics, vol. 124, pp. 139-147, 2016.

[9] L. R. Li, J. H. Deng, L. Zheng, and J. F. Liu, "Dominant frequency characteristics of acoustic emissions in white marble during direct tensile tests," Rock Mechanics and Rock Engineering, vol. 50, no. 5, pp. 1337-1346, 2017.

[10] J. P. Liu, Y. H. Li, S. D. Xu, S. Xu, C. Y. Jin, and Z. S. Liu, "Moment tensor analysis of acoustic emission for cracking mechanisms in rock with a pre-cut circular hole under uniaxial compression," Engineering Fracture Mechanics, vol. 135, pp. 206-218, 2015.

[11] Z. Moradian, H. H. Einstein, and G. Ballivy, "Detection of cracking levels in brittle rocks by parametric analysis of the acoustic emission signals," Rock Mechanics and Rock Engineering, vol. 49, no. 3, pp. 1-16, 2016.

[12] J. Zhang, W. H. Peng, F. Y. Liu, H. X. Zhang, and Z. J. Li, "Monitoring rock failure processes using the Hilbert-Huang transform of acoustic emission signals," Rock Mechanics and Rock Engineering, vol. 49, no. 2, pp. 427-442, 2016.

[13] X. G. Kong, E. Y. Wang, S. G. Li, H. F. Lin, P. Xiao, and K. Z. Zhang, "Fractals and chaos characteristics of acoustic emission energy about gas-bearing coal during loaded failure," Fractals, vol. 27, no. 5, Article ID 1950072, 2019.

[14] D. P. Ma, Basic experiment research of failure mechanism and precursory characteristics of rock under triaxial unloading confining pressure, Ph.D. thesis, Shandong University of Science and Technology, Shandong, China, 2016.

[15] B. Fu, Z. H. Zhou, H. Q. Wang, and Y. X. Wang, "Precursor information study on acoustic emission characteristics of marble under uniaxial cyclic loading-unloading," Journal of China Coal Society, vol. 41, no. 8, pp. 1946-1953, 2016.

[16] H. R. Li, C. H. Yang, Y. G. Liu, F. Chen, H. L. Ma, and B. W. Wang, "Experimental research on ultrasonic velocity and acoustic emission properties of granite under failure process," Chinese Journal of Geotechnical Engineering, vol. 36, no. 10, pp. 1915-1923, 2014.

[17] X. G. Kong, E. Y. Wang, S. G. Li, H. F. Lin, Z. B. Zhang, and Y. Q. Ju, "Dynamic mechanical characteristics and fracture mechanism of gas-bearing coal based on SHPB experiments," Theoretical and Applied Fracture Mechanics, vol. 105, p. 9, Article ID 102395, 2020.

[18] Y. L. Chen, M. Irfan, and C. P. Song, "Verification of the Kaiser effect in rocks under tensile stress: experiment using the Brazilian test," International Journal of Geomechanics, vol. 18, no. 7, Article ID 4018059, 7 pages, 2018.

[19] M. W. Zhang, Q. B. Meng, S. D. Liu, D. Y. Qian, and N. Zhang, "Impacts of cyclic loading and unloading rates on acoustic emission evolution and felicity effect of instable rock mass,"
Advances in Materials Science \& Engineering, vol. 2018, Article ID 8365396, 16 pages, 2018.

[20] Y. Zhang, Y. L. Chen, R. G. Yu, L. Q. Hu, and M. Irfan, "Effect of loading rate on the felicity effect of three rock types," Rock Mechanics and Rock Engineering, vol. 50, no. 6, pp. 1673-1681, 2017.

[21] B. Liu, Y. J. Ma, G. Zhang, and W. Xu, "Acoustic emission investigation of hydraulic and mechanical characteristics of muddy sandstone experienced one freeze-thaw cycle," Cold Regions Science and Technology, vol. 151, pp. 335-344, 2018.

[22] G. S. Su, Y. J. Shi, X. T. Feng, J. Q. Jiang, J. Zhang, and Q. Jiang, "True-triaxial experimental study of the evolutionary features of the acoustic emissions and sounds of rockburst processes," Rock Mechanics and Rock Engineering, vol. 51, no. 2, pp. 375-389, 2018.

[23] S. C. Tian, M. Sheng, Z. K. Li, H. K. Ge, and G. S. Li, "Acoustic emission characteristics of sedimentary rocks under highvelocity waterjet impingement," Rock Mechanics and Rock Engineering, vol. 50, no. 10, pp. 2785-2794, 2017.

[24] Q. S. Wang, J. X. Chen, J. Q. Guo, Y. B. Luo, H. Y. Wang, and Q. Liu, "Acoustic emission characteristics and energy mechanism in karst limestone failure under uniaxial and triaxial compression," Bulletin of Engineering Geology \& the Environment, vol. 78, no. 2, pp. 1427-1442, 2019.

[25] C. D. Zhang, W. G. Liang, Z. G. Li, S. G. Xu, and Y. S. Zhao, "Observations of acoustic emission of three salt rocks under uniaxial compression," International Journal of Rock Mechanics and Mining Sciences, vol. 77, pp. 19-26, 2015.

[26] J. Y. Fan, J. Chen, D. Y. Jiang, A. Chemenda, J. C. Chen, and J. Ambre, "Discontinuous cyclic loading tests of salt with acoustic emission monitoring," International Journal of Fatigue, vol. 94, pp. 140-144, 2017.

[27] J. Vilhelm, V. Rudajev, A. V. Ponomarev, V. B. Smirnov, and T. Lokajíček, "Statistical study of acoustic emissions generated during the controlled deformation of migmatite specimens," International Journal of Rock Mechanics and Mining Sciences, vol. 100, pp. 83-89, 2017.

[28] Y. X. Gong, Z. J. Song, M. C. He, W. L. Gong, and F. Q. Ren, "Precursory waves and eigenfrequencies identified from acoustic emission data based on singular spectrum analysis and laboratory rock-burst experiments," International Journal of Rock Mechanics and Mining Sciences, vol. 91, pp. 155-169, 2017.

[29] P. Rodríguez, P. B. Arab, and T. B. Celestino, "Characterization of rock cracking patterns in diametral compression tests by acoustic emission and petrographic analysis," International Journal of Rock Mechanics and Mining Sciences, vol. 83, pp. 73-85, 2016.

[30] Y. J. Yang, H. Q. Duan, L. Y. Xing, and L. Deng, "Fatigue characteristics of coal specimens under cyclic uniaxial loading," Geotechnical Testing Journal, vol. 42, no. 2, pp. 331-346, 2019.

[31] S. C. Li, Deformation and damage law and its nonlinear characteristics of rock under cyclic load, Ph.D. thesis, Chongqing University, Chongqing, China, thesis, 2008.

[32] Y. M. Bai, "Experimental research on the fatigue property of salt rock under cyclic loading," M.S. thesis, Chongqing University, Chongqing, China, thesis, 2012.

[33] J. P. Zou, W. Z. Chen, D. S. Yang, J. Q. Yuan, and X. J. Tan, "Mechanical properties and damage evolution of coal under cyclic loading conditions," Journal of China Coal Society, vol. 41, no. 7, pp. 1675-1682, 2016.

[34] M. Chen, S. Q. Yang, Y. C. Zhang, and C. W. Zang, "Analysis of the failure mechanism and support technology for the 
dongtan deep coal roadway," Geomechanics and Engineering, vol. 11, no. 3, pp. 401-420, 2016.

[35] Itasca Consulting Group Inc, Manual of Particle Flow Code (Version 5.0), Itasca Consulting Group Inc., Minneapolis, MN, USA, 2016.

[36] Y. L. Zhang, Numerical Simulation Study on the Landslide Process and Impact Disaster, M.S. thesis, Hohai University, Nanjing, China, thesis, 2014.

[37] K. Mu, T. B. Li, J. Yu et al., "Mesoscopic simulation of relationship of acoustic emission and compressive deformation behavior in sandstone under confining pressures effect," Chinese Journal of Rock Mechanics and Engineering, vol. 33, no. S1, pp. 2786-2793, 2014.

[38] H. L. Liu, P. T. Wang, T. H. Yang, T. Xu, Q. L. Yu, and D. Xia, "Mechanical characteristics of granite under uniaxial compressive and ae monitoring test using particle flow code," Journal of China Coal Society, vol. 40, no. 8, pp. 1790-1795, 2015.

[39] M. X. Zhang, "Study on fatigue characteristics and damage behavior of cemented-stabilized soil under cyclic loading," M.S. thesis, Fuzhou University, Fuzhou, China, 2004.

[40] J. Q. Xiao, D. X. Ding, F. L. Jiang, and G. Xu, "Fatigue damage variable and evolution of rock subjected to cyclic loading," International Journal of Rock Mechanics and Mining Sciences, vol. 47, no. 3, pp. 461-468, 2010. 